\title{
"Trans-tattoo in immersion" method for the removal of a recurrent, previously tattooed adenoma using endoscopic submucosal hydrodissection
}

An obese 74-year-old man, who underwent two unsuccessful endoscopic mucosal resections of a laterally spreading lesion nongranular type in the transverse colon was referred to our hospital. The lesion had been tattooed directly with SPOT (GI Supply, Camp Hill, Pennsylvania, USA) in order to aid surgical resection ( $\triangleright$ Fig. 1). Prior biopsies reported adenoma with high-grade dysplasia. Colorectal surgeons referred the patient for endoscopic salvage treatment.

Therapeutic endoscopy was performed using endoscopic submucosal dissection (ESD) with the ERBEJET 2 hydrodissection system and Hybrid Knife T-type (ERBE Elektromedizin, Tübingen, Germany) ( $\vee$ Video 1$)$. The lesion was elevated using selective-regulation high-pressure waterjet method [1]. Immersion in saline solution was used to facilitate view of the dissection plane. The submucosal layer showed fatty tissue, severe fibrosis, and a previous tattoo ( $\vee$ Fig. 2 ). Around the densely tattooed area, ESD was performed using "trans-tattoo in immersion" (ESD-TTI), involving four elements ( Fig.3): immersion in saline solution, water pressure method [2], Hybrid Knife probe mode [3], and hydrodissection. This technique enables clear vision of the tattooed area, improving the dissecting process at the level of the deep submucosal plane located parallel to the muscular layer.

The resection was completed within 121 minutes without adverse events ( Fig.4). The resected specimen size was $20 \times 30 \mathrm{~mm}$ (> Fig.5a). Pathology examination revealed a tubular adenoma with an area of high-grade dysplasia and free resection margins. Photomicrograph showed fatty tissue, fibrosis, tattoo, and muscle fibers from the main muscle layer ( $\mathbf{F i g . 5} \mathbf{b}$ ).

Tattooing causes fibrosis making dissection more difficult and reducing the

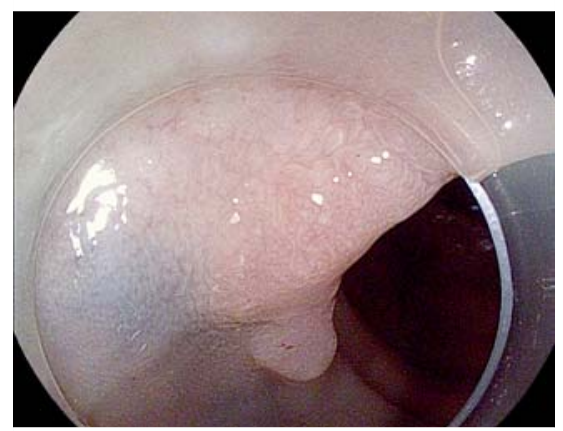

- Fig. 1 Recurrent lesion after two piecemeal endoscopic mucosal resection procedures, showing evidence of previous tattoo around and inside the lesion.

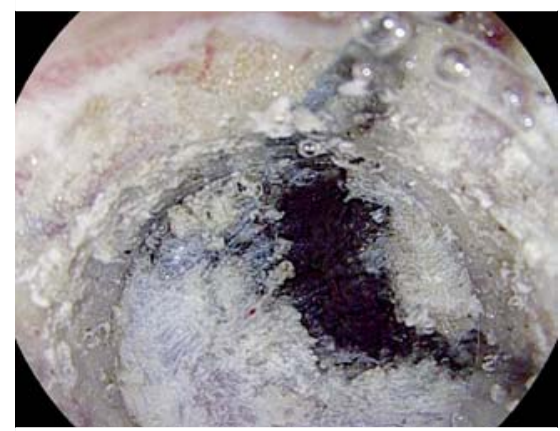

- Fig. 2 The submucosal layer showed fatty tissue and severe fibrosis in addition to the previous tattoo.

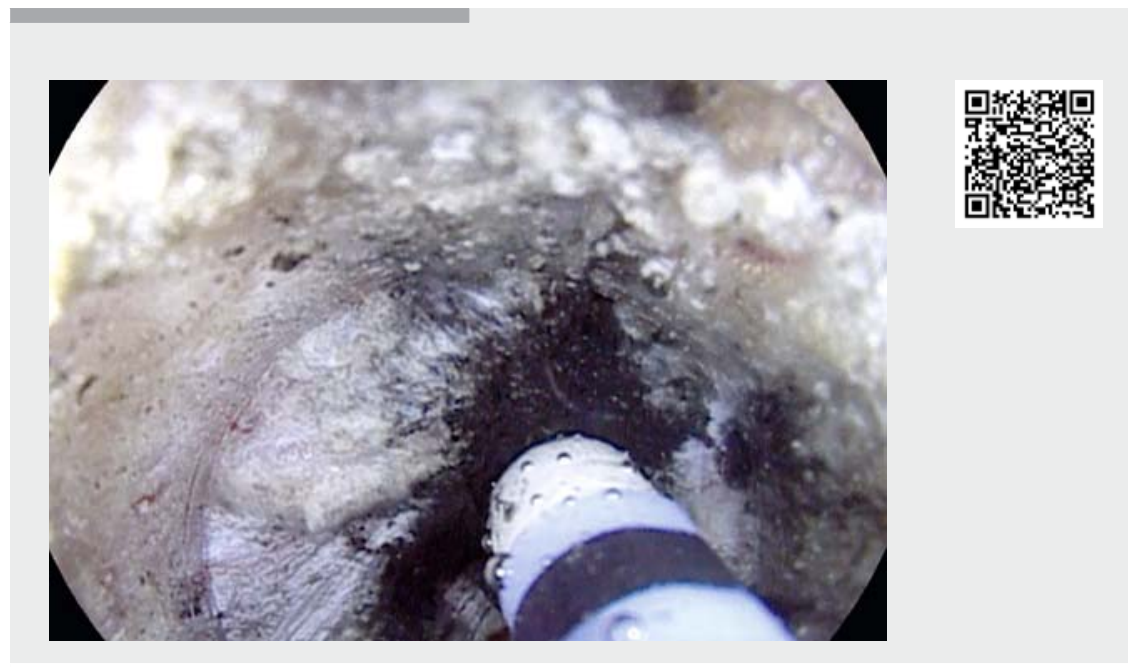

Video 1 Endoscopic submucosal dissection of a recurrent, previously tattooed adenoma using the "trans-tattoo in immersion" method.

chance of en bloc resection [4]. This case report, similarly to previous ones [5], demonstrates that despite some technical difficulties, ESD procedures greatly facilitate en bloc resection. Further studies are needed to assess the efficacy and safety of ESD-TTI for the removal of tattooed lesions.

Endoscopy_UCTN_Code_TTT_1AQ_2AD

\section{Competing interests}

The authors declare that they have no conflict of interest. 


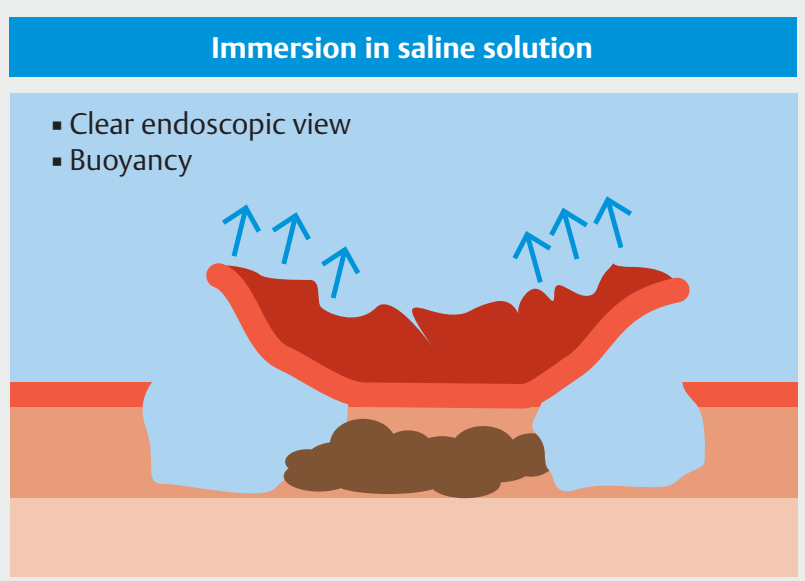

Hybrid knife probe mode

- Delicate dissection

- Small pulses of pressure, safe cut

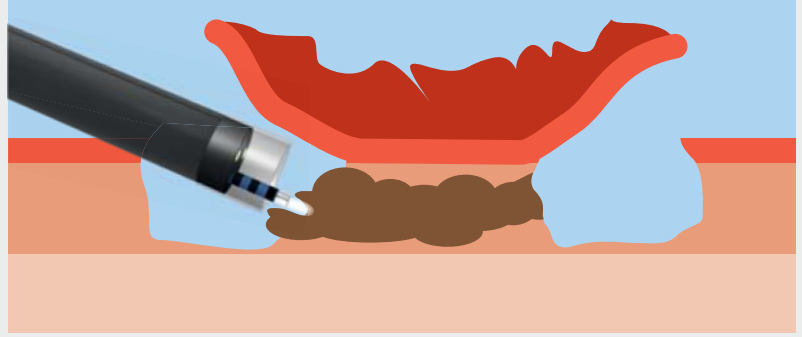

\section{Water pressure method}

- Traction effect

- Cleaning of detached tattoo fragments

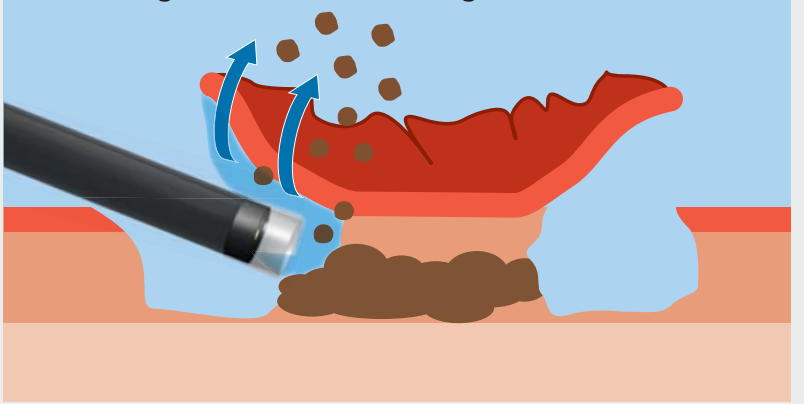

Hydrodissection

- High-pressure waterjet improves dissection

- Debilitation \& separation in tattoo area

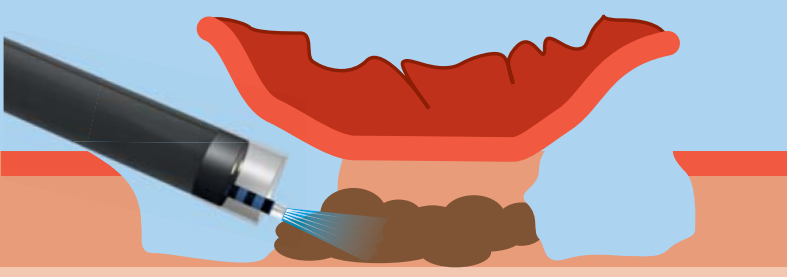

Fig.3 Graphical representation of endoscopic submucosal dissection with "trans-tattoo in immersion" method.

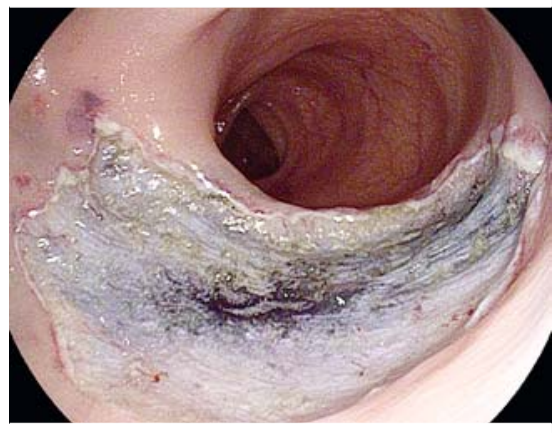

> Fig. 4 Resection surface.
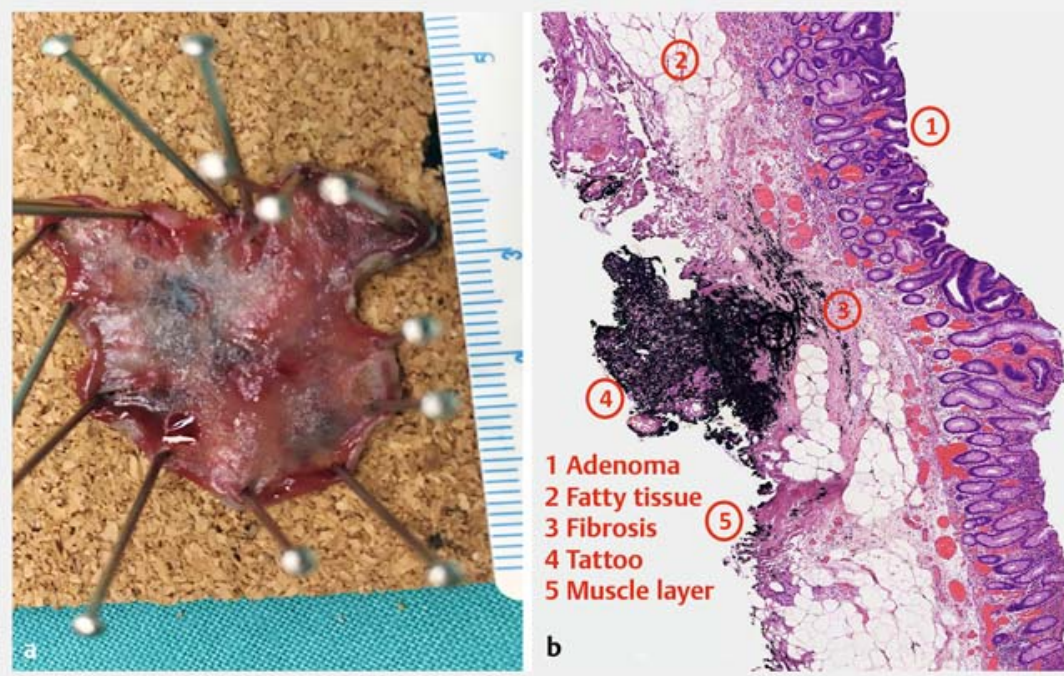

- Fig. 5 Post-procedure. a The resected specimen. b Histological examination. 
The authors

Felipe Ramos-Zabala ${ }^{1,2}$, Cristina Gil-Páez ${ }^{1,2}$, Alejandra Alzina-Pérez ${ }^{1,2}$, Sara BlascoAlgora $^{1,2}$, Jorge Vásquez-Guerrero ${ }^{2,3}$, Rocío Cardozo-Rocabado ${ }^{4}$, Luis Moreno-Almazán 1,2

1 Department of Gastroenterology, HM Montepríncipe University Hospital, HM Hospitales Group, Boadilla del Monte, Madrid, Spain

2 Department of Clinical Sciences, School of Medicine, University of CEU San Pablo, Boadilla del Monte, Madrid, Spain

3 Department of Gastroenterology, HM Puerta del Sur University Hospital, HM Hospitales Group, Móstoles, Madrid, Spain

4 Department of Pathological Anatomy, HM Puerta del Sur University Hospital, Móstoles, Madrid, Spain

\section{Corresponding author}

Felipe Ramos-Zabala, MD, PhD

Department of Gastroenterology and Department of Clinical Sciences, HM Montepríncipe University Hospital, School of Medicine, University of CEU San Pablo, Av. de Montepríncipe, 25, 28660 Boadilla del Monte, Madrid, Spain Fax: +34-91-7089900

framoshdiaz@gmail.com

\section{References}

[1] Ramos-Zabala F, Beg S, García-Mayor M et al Novel approach to endoscopic submucosal dissection of a cecal lesion with non-lifting sign by submucosal fatty tissue using selective-regulation high-pressure water-jet method and immersion in saline solution. VideoGIE 2020; 5: 116-119

[2] Yahagi N, Nishizawa T, Sasaki M et al. Water pressure method for duodenal endoscopic submucosal dissection. Endoscopy 2017; 49: E227-E228

[3] Ramos-Zabala F, García-Mayor M, Domínguez-Pino A et al. Combination of immersion in saline solution, pocket-creation method, water-jet hydrodissection, and hybrid knife "probe mode" simplifies endoscopic submucosal dissection in giant rectal polyp. VideoGIE 2019; 4: 478-480

[4] Ono S, Fujishiro M, Goto O et al. Endoscopic submucosal dissection for colonic laterally spreading tumors is difficult after target tattooing. Gastrointest Endosc 2009; 69: 763-766

[5] Chiba H, Tachikawa J et al. Successful endoscopic submucosal dissection of colon cancer with severe fibrosis after tattooing. Clin J Gastroenterol 2017; 10: 426-430
Bibliography

Endoscopy 2020; 52: E408-E410

DOI 10.1055/a-1147-1206

ISSN 0013-726X

published online 24.4.2020

(c) 2020. Thieme. All rights reserved.

Georg Thieme Verlag KG, Rüdigerstraße 14,

70469 Stuttgart, Germany

\section{ENDOSCOPY E-VIDEOS}

https://eref.thieme.de/e-videos

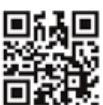

Endoscopy E-Videos is a free access online section, reporting on interesting cases and new techniques in gastroenterological endoscopy. All papers include a high quality video and all contributions are freely accessible online.

This section has its own submission website at https://mc.manuscriptcentral.com/e-videos 